\title{
Signal processing algorithm for auto- detection of atmospheric boundary layer (ABL) height from LIDAR signals
}

\author{
G.Nagamuni Pradeep $^{\# 1}$, Y.B.Kumar ${ }^{* 2}$, T.Venkateswarlu ${ }^{\# 3}$

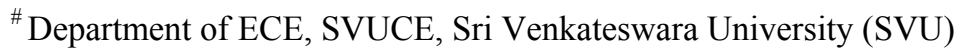 \\ Tirupati-517502, Andhra Pradesh (AP), India \\ 1.pratheepgn408@gmail.com \\ ${ }^{3}$ tvenkateswarlu@svuniversity.ac.in \\ * National Atmospheric Research Laboratory (NARL) \\ Gadanki-517112, PakalaMandal, Chittoor (District), Andhra Pradesh (AP), India \\ 2ypbk@narl.gov.in
}

\begin{abstract}
The atmospheric boundary layer (ABL), the lowest layer of the atmosphere, is a highly dynamic layer that is influenced byseveral parameters such as surface heating, turbulence, moisture transport etc.,. The detection of the height of ABL plays a crucial role in aviation, pollution monitoring,meteorology and agriculture sectors. At present, several methods are available to identify the height of the boundary layer (BL), however with coarse temporal and spatial resolutions. LIDAR offers high resolution measurements oncontinuous basis. LIDAR is one of the active remote sensors of atmosphere works on the principle of radar but employs laser with fine pulse widths. LIDAR technique has been employed to study the altitude profiles of aerosols, clouds, winds,temperature and humidity layers in the atmosphere. In this paper, we show a signal processing methodology to derive the ABL height from LIDAR signals. The signal processing methodology uses different analytical techniques such as Gradient, IPM, LGM, Variance and Wavelet as its modules to derive the height of ABL on an automatic basis. The automatic detection of ABL height from LIDAR signals employs an algorithm that employs a correlation process that works on inter-comparison results between different analytical methods. All these processes undergo in a systematic manner to present the ABL height detection automatically over a period of time frame set. The minimum time period required for detection of ABL height on automatic basis needs half-hour time period. In this presentation, we show the results of LIDAR measurements corresponds to convective period and present the detection of ABL height using the above signal processing algorithm.
\end{abstract}

Keywords-Atmosphere, ABL, Remote sensing, aerosols, LIDAR

\section{INTRODUCTION}

ABL is a thin dusty layer that exists near the earth's surface. This layer contains a large part of particulate matter (PM) and other pollutants. Everyday several tons of PM is injected into the ABL by natural and manmade sources exist on the Earth's surface. Differential heating of landmasses generates winds in this layer. Winds play a key role in the transport and mixing of PM. The vertical column of PMchanges during the ABL evaluation. The ABL thickness varies with time and location on land surfaces. The thickness of ABL depends on the solar energy reaching the earth's surface. Land areas associated with strong convection and large winds mark deep ABL [1]. Shallow ABL exists over low temperate zones. This dusty layer acts as a dynamical fluid and the top portion of the layer undergo severe fluctuations during convective periods. Determination of ABL thickness during convective periods is difficult. In-situ and remote sensing methods are available to estimate ABL thickness. The atmospheric parameter, ABL thickness, is required for agriculture, meteorology, and aviation sectors. Radiosondes connected to Hydrogen filled balloons provide the in-situ or direct measurements of ABL thickness [2],[3].These units equipped with sensors for measurement of pressure, temperature, and humidity parameters of the atmosphere. The pressure of Hydrogen inside balloon decides the ascent rate of the balloon that provides the height resolution of parameter measurement. The sondes provide parameter data on $400 \mathrm{MHz}$ radio frequency to ground station. The ABL thickness over a particular location provided by this method is not accurate due to theinfluence of local winds on balloon trajectory [3]. However, remote sensing methods provide measurements over a particular location. Remote sensing measurements provide indirect measurements of $A B L$ thickness from different platforms such as satellite [4]-[6], airborne [7] and ground based instruments [8],[9]. Ground based LIDARs provide high resolution measurements of ABL thickness or height and have been compared with other operational methods [10]. 
In this paper, we present a signal processing algorithm that identifies the ABL thickness or height automatically from LIDAR signals. The algorithm uses several analytical methods such as gradient, variance and wavelet methods and utilizes a correlation matrix for auto detection of ABL height. The auto-detection process performs inter-comparison between outcomes of different analytical methods mentioned above. Thecommon higher correlative method is selected using correlation matrix and the outcome of the ABL thickness or height from that method is considered. The algorithm was developed in MATLAB platform and was subjected to LIDAR signals that collected at different timings.

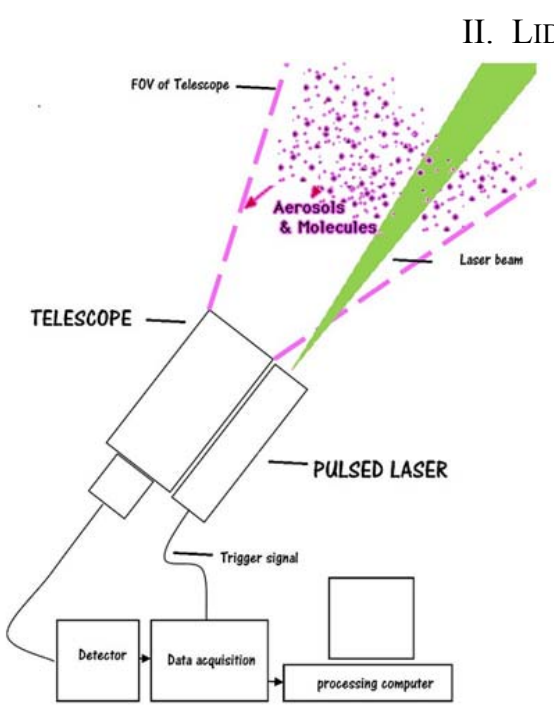

Fig.1 LIDAR block diagram

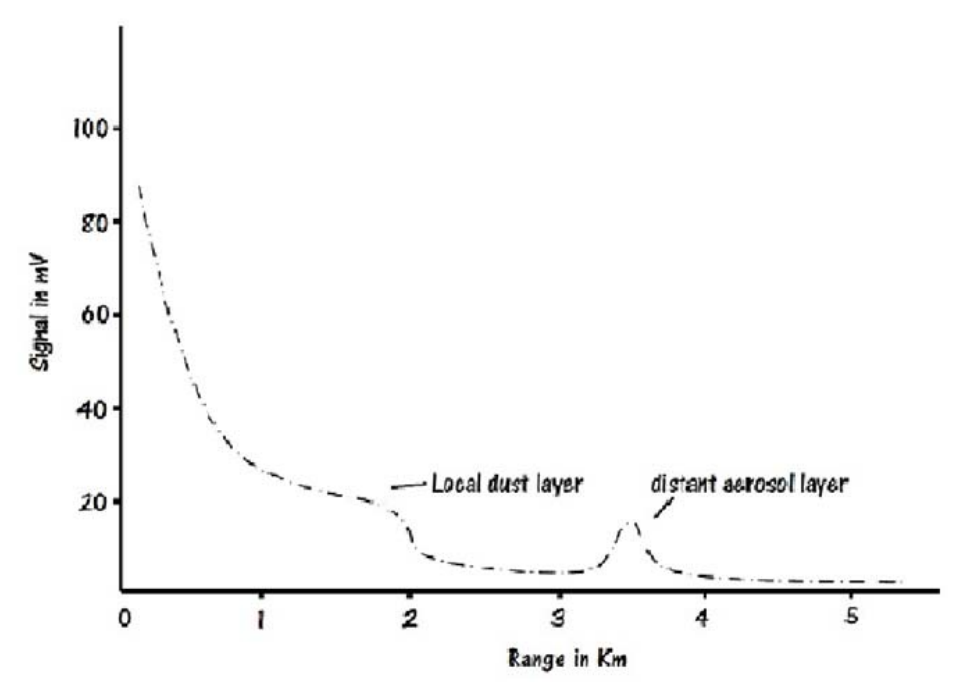

Fig.2Basic LIDAR signal showing different aerosol layers

The signals used in this paper taken from a LIDAR system. The LIDAR system used in this experiment consistsof atransmitter, light collector unit, detector, signal acquisitionsubsystem and processing computer [8] as shownin Fig.1. The transmitter unit fires pulses of the laserinto the atmosphere. In this work, we employed a $532 \mathrm{~nm}$ laser of $5 \mathrm{~ns}$ pulse width withrepetition rate of $20 \mathrm{~Hz}$ and beam width of 700 micro radians. In this LIDAR design, no beam expander was employed. Usually, telescopes are employed as light collectors that collect backscattered laser light from the atmosphere. A 150mmdia telescope was employed as the light collator in this LIDAR. Our LIDAR system uses a photo-multiplier tube (PMT) as a light detector. This pmt was maintained at room temperatures during the LIDAR operation. A transient recorder system employs 12 bit ADC used as signal acquisition unit. The transient recorder was operated at a sampling frequency of $20 \mathrm{MHz}$ which can provide basic time resolution as $50 \mathrm{nsec}$. The time resolution $50 \mathrm{nsec}$ corresponds to a range resolution of 7.5 meters. The transient recorder can be set to operate at different time integration periods. In this work, time integration of one minute or 60 seconds is considered for basic LIDAR signal generation. The LIDAR signal averaged over 60 seconds or 1200 laser pulses produced by transient recorder as a basic raw signal. These raw signals with time and date tagged are stored in the memory of processing computer automatically using software that controls the transient recorder system. Such raw signals collected over a period of 26 hours on a continuous basis, which isstored in a separate folder are employed in this work for analysis and examination. Fig. 2 illustrates the signature of typical LIDAR raw signal collected at 1000 LT on 21 October 2009. One can see the LIDAR detected aerosol layers. This is illustrated in Fig.2. A distant aerosol layer transported from long range is also shown in Fig.2.

\section{METHOD OF DATA ANALYSIS}

LIDAR operation involves sending of laser pulses into the atmosphere and collecting the backscattered laser radiation at the ground. In this process, the LIDAR signal suffers from extinction posed by the presence of particles and molecules in the path of the laser propagation through the atmosphere. Hence the collected signal at the ground needs a correction from the above process before utilization. The signal collected at ground is represented as indicated, which is given by [11],

where, $P(r)=$ Signal received at ground

$$
P(r)=\frac{C \beta(r) T^{2}}{r^{2}}+P_{b}
$$

$P_{b}=$ Background noise

$\mathrm{C}=$ Lidar system constant

$$
\beta(r)=\beta_{a}(r)+\beta_{m}(r)
$$


$\beta(r)=$ Total backscattrered coefficient $\beta_{a}(r)=$ Aerosoles backscattered coefficient $\beta_{m}(r)=$ Molecularbackscattered coefficient

$$
T^{2}=\exp \left(-2 \int_{0}^{\infty} \alpha d r\right)
$$

$\mathrm{T}=$ The atmospheric transmittance experienced by the laser photons while propagation in the atmosphere

The LIDAR collects backscattered signals at the ground in raw form. The raw form LIDAR signal is such that its structure contains both header and data. The header is in American Standard Code for Information Interchange (ASCII) form but the data is in binary form. The data is first converted into ACII form using a code developed in MATLAB and then the pre-processing works like denoising, range correction and normalization were carried out as shown in equations 2 to 4 .

Equation 2 represents denoised signal

Equation 3 represents range corrected signal(RCS)

$$
P(r)-P_{b}=\frac{C \beta(r) T^{2}}{r^{2}}
$$

$$
\left[\mathrm{P}(\mathrm{r})-\mathrm{P}_{\mathrm{b}}\right] \mathrm{r}^{2}=\mathrm{C} \beta(\mathrm{r}) \mathrm{T}^{2}
$$

Equation 4 represents noramlization of Range corrected signal

$$
\beta(\mathrm{r}) \mathrm{T}^{2}=\frac{\left[\mathrm{P}(\mathrm{r})-\mathrm{P}_{\mathrm{b}}\right] \mathrm{r}^{2}}{\mathrm{C}}
$$

\section{ANALYTICAL METHODS AND SIGNAL PROCESSING METHODS TO FIND ABL HEIGHT}

There are several methods developed to find ABL height from LIDAR signals. Mainly we divide these into three categories. They come under differential, statistical and wavelet based techniques [12].

\section{A. DIFFERENTIAL METHODS:}

The differential method uses three different types of differentiation to find out the ABL height. These methods are given briefly here.

1) Gradient method:The gradient method is one of the mathematical methods, gives a mean of deriving boundary layer height by performing the first derivative of normalized range corrected signal [13]-[15]. It was explained mathematically by equation 5 .

$$
h_{G M}=\min \left\{\frac{d[X(r)]}{d r}\right\}
$$

where $\mathrm{x}(\mathrm{r})$ is normalised range corrected signal(NRCS). The NRCS data and corresponding height is given by the gradient method were shown in Fig.3.

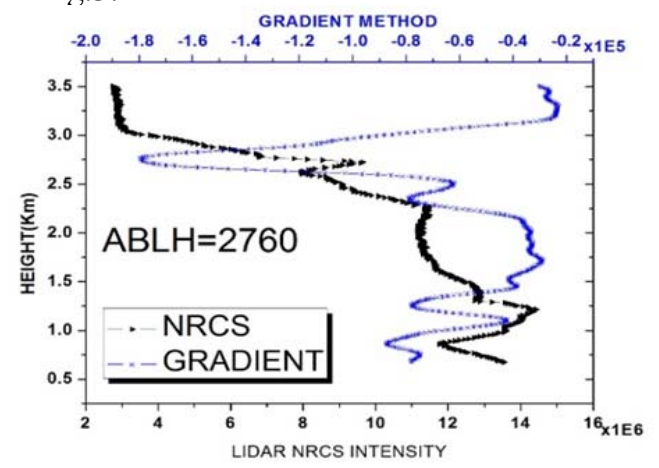

Fig.3 Gradient method utilized to estimate ABL height

2) Double Gradient Method: This method has beendeveloped to find out the inflection point at the top of the boundary layer [16], [17].It is explained by the equation 6 .

$$
h_{I P M}=\min \left\{\frac{d^{2}[X(r)]}{d r^{2}}\right\}
$$

where $\mathrm{x}(\mathrm{r})$ is normalised range corrected signal(NRCS). The NRCS data and corresponding height given by the IPM method were shown in Fig.4. 


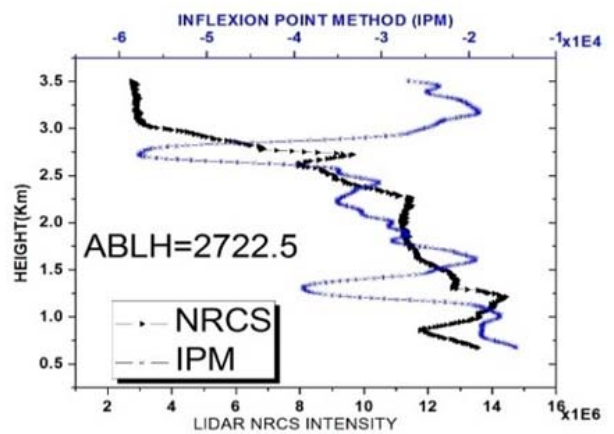

Fig.4 ABL height derived using the inflection point method

3) Logarithmic Gradient Method: This method uses application of logarithm to the NRCS data. Later we apply gradient to the signals to obtain the first derivative. The first derivative provides the height of the ABL [18], [19]. However, this method fails to describe small structural changes in atmosphere. The equation 7 gives the full mathematical idea about logarithmic gradient.

$$
h_{L G M}=\min \left\{\frac{d[\ln (X(r))]}{d r}\right\}
$$

where $\mathrm{x}(\mathrm{r})$ is normalised range corrected siganal(NRCS). The NRCS data and corresponding height given by the LGM method were shown in Fig.5.

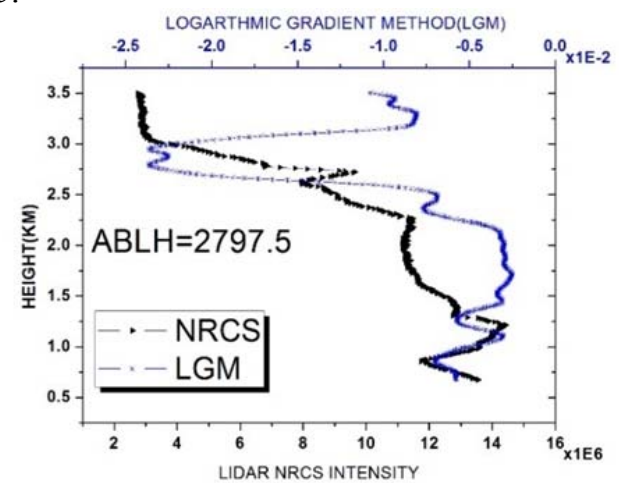

Fig.5Application of logarithmic gradient method to LIDAR signals

B. VARIANCE METHOD

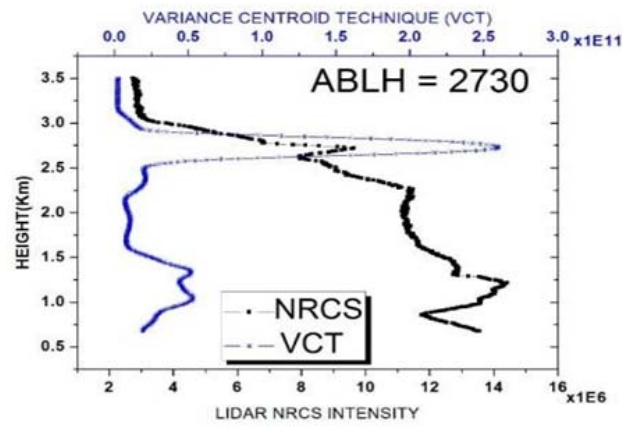

Fig.6 Statistical variance method used for estimation of ABL top

The most skilled or versatile statistical method to find ABL height is variance method in this method we select one profile as the centroid and above centroid and below centroid,we select 15 profiles.equation8 provides the variance of the backscattered lidar signals at the top of the boundary layer. the drawback of this method is ,it requires large averaging of signals hence lose the temporal resolution of the signal.

$$
\sigma_{\mathrm{X}(\mathrm{r})}=\frac{1}{N} \sum_{i=1}^{N}\left[X_{i}(r)-\bar{X}^{2}\right.
$$

where $\mathrm{N}$ represents the no of profiles. Fig. 6 represents the variance for \pm 15 profiles of lidar signals and shown abl height given by variance method [20], [21]. 


\section{WAVELET COVARIANCE TRANSFORM METHOD}

When temporal periods are very small or short the above analytical methods are not sufficiently detect theABL height. Hence, an advanced signalprocessingmethodis required. This method can use HAAR or COVARIANCE transform (WCT) method to identify the ABL height. Recently it is found that WCT is a most preferable method to find ABL top because it is very fast and the lack of prior knowledge to use it effectively. The math under consideration describes the wavelet equation given at 9 and 10 .

$$
\begin{gathered}
\mathrm{h}\left(\frac{r-b}{a}\right)=\left\{\begin{array}{ccc}
+1 & : & b-\frac{a}{2} \leq \mathrm{r}<b \\
-1: & b \leq \mathrm{r}<b+\frac{a}{2} \\
0: & \text { otherwise }
\end{array}\right. \\
w_{f}(a, b)=\frac{1}{a} \int_{r_{b}}^{r_{t}} X(r) \mathrm{h}\left(\frac{r-b}{a}\right)
\end{gathered}
$$

where, $\mathrm{x}(\mathrm{r})$ is normalized range corrected signal, $\mathbf{r}$ is the range, $\mathbf{b}$ is the centre of the haar function also known as the translation valueand $\mathbf{a}$ is dilation of the function. for detecting atmospheric height find the sharp changes in the signal,it basically a combination of haar transform with translator function. Here we took translation value from previous methods heights. The drawback of this method is the selection of translation value is more difficult. The Fig.7 shows ABL height using WCT method [22]-[24].

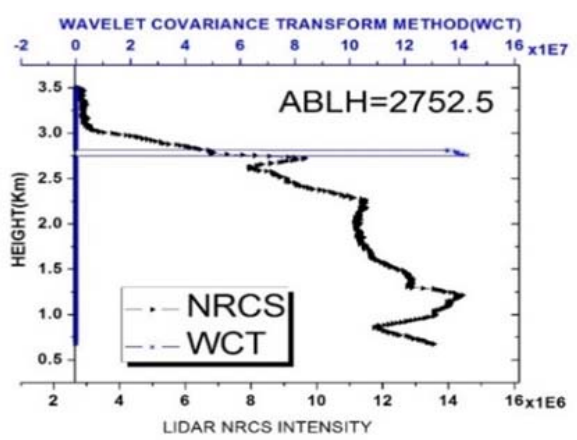

Fig.7 Wavelet based technique to estimate the ABL top

\section{OPTIMAL METHOD OF FINDING ABL HEIGHT}

The gradient, statistical and wavelet methods explained above have been applied to LIDAR signals to derive the ABL height. Since these methods differ from each other the detected ABL height using these methods is different. In order to find out consistence and reliable method, we utilized the outcome of all the above methods into a matrix. This is a matrix of the order $5 \times 5$. This matrix row and columns represents the outcome of correlative output of the methods compared. The obtained correlation matrix is shown in Fig. 8 . In this matrix the maximum value is given by unity. This matrix' principle diagonal represents the location of maximum correlation given by unity. It is observed that the WCT method is reaching the better correlation among the methods compared. The process of executing correlation matrix and identification of common method is done an automatic basis using a code written in MATLAB. The sequence of algorithm shown by the code is presented in Fig.9. The auto detection of ABL height needs atleast half an hour integration time of LIDAR signals.

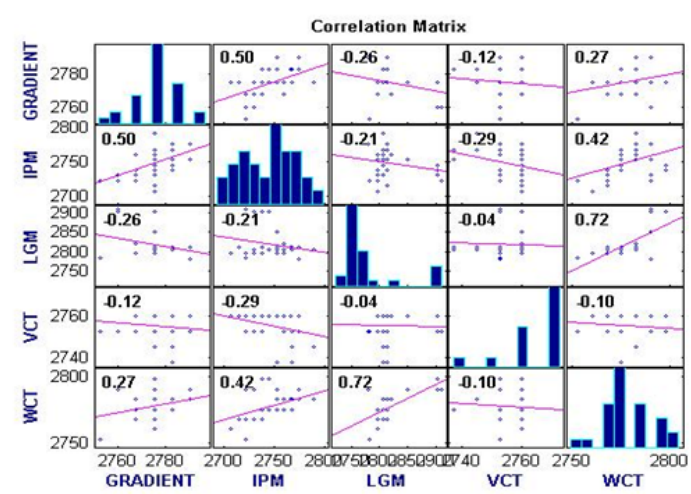

Fig.8 DerivedCorrelation Matrix for detecting optimal ABL height 


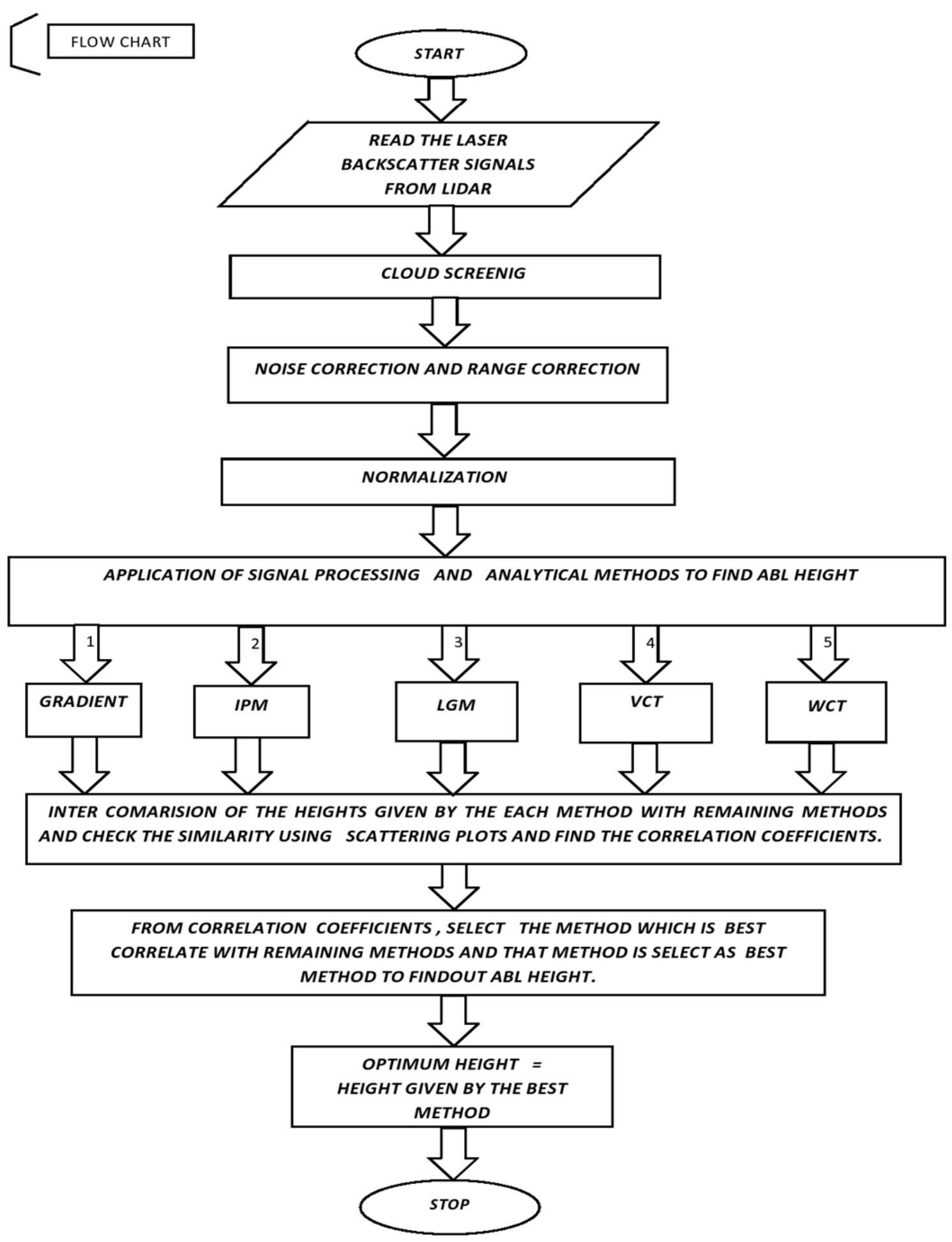

Fig.9 Flowchart showing the process of developed algorithm

\section{CONCLUSION}

In this paper we developed a new algorithm to find out optimalheight of ABL automatically with the help of 5 methods and correlation technique from the backscattered signals of LIDAR. Finally we concluded that WCT gives best results comparing to remaining methods. Here we used MATLAB software to develop this proposed algorithm. It was checked by applying the different LIDAR profiles and gives good results. Finally we concluded that this algorithm worked efficiently to find ABL height at different situations of atmosphere. 


\section{ACKNOWLEDGMENTS}

The prime author of the article Mr. G.NagamuniPradeep, studying M.Tech at SVU college of Engineering (SVUCE),Tirupati would like to thank to AICTE for providing the MTP stipend.One of the authors, Dr.Y.Bhavani Kumar, Scientist SF, of NARL would like to thank the officials of Department of Space(DOS), Government of India for funding the LIDAR project at NARL site, Gadanki

\section{REFERENCES}

[1] R.B .Stull, An Introduction to Boundary layer meteteorology, Kluwer academic publishers. 1988.

[2] X.Y.Wang, and K.C.Wang., "Estimation of Atmospheric Mixing layer height from Radiosonde data", Atmos.Means.Tech 7(6):17011709., 2014

[3] D. J .Seidel., C. O. Ao, and K. Li ,"Estimating Climatological Planetary Boundary Layer Heights From Radiosonde Observations: Comparison of Methods and Uncertainty Analysis",J.Geophys, Res., 115: D16113, 2010.

[4] C.O.Ao,T.K. Chan, B.A.Iijima, j.-L.Li,A.J.Mannucci, j.Teixeira, B.Tian, and D.E.Waliser, "Planetary Boundary Layer Information From GPS Radio Occultation Measurements" GRAS SAF Workshop on Application of GPSRO Measurements 123-131,2008.

[5] F.Xie., D. L. Wu, C. O. Ao, A. J. Mannucci and E. R. Kursinski, “Advances And Limitations Of Atmospheric Boundary Layer Observations withGPS Occultation over Southeast Pacific Ocean", Atmos. Chem. Phys., 12(2): 903-918., 2012

[6] S. S.Prijith., P. V. N. Rao, P. Sujatha, V. K. Dadhwal, "Estimation Of Planetary Boundary Layer Height Using Suomi NPP-Cris Soundings", Remote Sens. Lett. 7(7), 621-630., 2016

[7] K. J.Davis., N. Gamage, , C. R. Hagelberg, C. Kiemle, D. H. Lenschow and P. P. Sullivan, An Objective Method For Deriving Atmospheric Structure from Airborne Lidar Observations,J. Atmos. Oceanic Technol., 17(11): 1455-1468., 2000

[8] Y. Bhavani Kumar., Portable lidar system for atmospheric boundary layer measurements, Opt. Eng. 45(7) 076201,2006

[9] B.Hennemuth and A.Lammert, "Determination of the atmospheric boundary layer height from radiosonde and lidar backscatter", Boundary-Layer Meteorol.,120(1): 181-200.,2006

[10] P.Seibert., F. Beyrich, S. E. Gryning, S. Joffre, A. Rasmussen, and P. Tercier"ReviewAnd Intercomparison Of Operational Methods For The Determination Of The Mixing Height", Atmos. Environ., 34(7): 1001-1027.,2000.

[11] R.T.H. Collis “ Lidar: A new atmospheric probe", Quarterly journal of the royal meteorological society,vol 92, issue 392,pages 220230,april,1966

[12] R.Vishnu,Y.BhavaniKumar,P.R.Sinha,T.NarayanaRao and E.JamesJebaseelan Samuel "Retrieval of mixed layer height(MLH) from lidar using analytical methods and estimation of MLH growth rates over atropical site Gadanki", proceedings.spie digital library, $2016,21^{\text {st }}$ October.

[13] T. Luo, R. Yuan, and Z.Wang "Lidar-based remote sensing of atmospheric boundary layer height over land and ocen" PublishedbyCopernicus Publications on behalf of the European Geosciences Union, 22 January 2014

[14] Dai Cheng-Ying, Gaozhi-Qiu, Wang Qing, and Cheng Gang "Analysis of Atmospheric Boundary Layer HeightcharactersticsOver the Arctic Ocean Using the Aircraft and GPS Soundings" Atmospheric and Oceanic Science Letters, Vol.4, NO.2, 124-130, 2011

[15] F. Navas-Guzmán, J. L. Guerrero-Rascado, A. B. Fernández-Medina ,J. A. Adame and L. Alados-Arboledas "Mixing Layer Height. Determination by Lidar and Radio soundingData "Cite abstract as Author(s), Title, European Aerosol Conference, Salzburg, Abstract T20A014, 2007

[16] Stefan Emeis1, Klaus Schafer andChristophMunkel "Surface-based remote sensing of the mixing-layer height-Review" MeteorologischeZeitschrift, Vol. 17, No. 5, 621-630 October 2008

[17] Gregori de A. Moreiraa, RiadBourayoua, Fábio J. da Silva Lopesa, Taciana A. Albuquerqueb, Neyval C. Reis Jr.b, Gerhard Heldc, Eduardo Landulfoa “Automatic Methods to Detect the Top of Atmospheric Boundary Layer"Lidar Technologies, Techniques, and Measurements for Atmospheric Remote Sensing IX, edited by Upendra N. Singh, GelsominaPappalardo,Proc. of SPIE Vol. 8894, 88940T (C) 2013 SPIE.

[18] Y.Bhavanikumar and S.Purushottam, "Mathematical algorithms for determination of mixed layer height from laser radar signals",International journal of computer scince and engineering, 2(6):2059-2063, 2010.

[19] S. Pal, A. Behrendt, and V. Wulfmeyer "Elastic-Backscatter-Lidar-Based Characterization of the Convective Boundary Layer and Investigation of Related Statistics" Ann. Geophys., 28, 825-847, 2010.

[20] LaurentMenut, CyrilleFlamant, Jacques Pelon, and Pierre H.Flamant"Urban boundary-layer height determination from lidarMeasurements over the Paris area"Applied opticsY Vol. 38, No. 6 y 20 February 1999.

[21] Giovanni Martucci, Renaud Matthey, andValentinMitev"Comparison between Backscatter Lidar andRadio Sonde Measurements of the Nocturnal Stratification in the Lower Troposphere" Journal of Atmospheric And oceanic Technology, Vol.24, 2007.

[22] M.J. de Haij, W.M.F. Wauben, H. Klein Baltink, A. Apituley, "Determination of the Mixing Layer Height by A Ceilometer"Proceedings of the 8th International Symposium on Tropospheric Profiling, ISBN 978-90-6960-233-2 Delft, The Netherlands, October 2009

[23] I.M.Brooks.,"FindingBoundary Layer Top: Application Of A Wavelet Covariance Transform To Lidar Backscatter Profiles". J. Atmos.Ocean.Technol, Vol. 20, pp. 1092-1105., 2003.

[24] RajithaPaleti,Y.Bhavani Kumar and T.Krishnachaitanya, "Wavelet Transform Method For Deriving Atmospheric Boundary Layer Height From Lidar Signals”, 5(2), International Journal of Engineering and Technology,5(2):Apr-May 2013

\section{AUTHOR PROFILE}

Mr.G.NagamuniPradeepis currently doing M.Tech in the stream of communication systems in the Department of Electronics and Communication Engineering, Sri Venkateswara University College of Engineering (SVUCE),Tirupati, Andhra Pradesh, India.

Dr.Y.Bhavani Kumar is Scientist SF and Leader of LIDAR project at NARL, Department of Space, Government of India.

Dr.T.Venkateswarluis currently with department of ECE as a professor and chairman Board of service, SriVenkateswara University College of Engineering (SVUCE),Tirupati, Andhra Pradesh, India. 